\title{
Urinary 1-hydroxypyrene concentrations in coke oven workers
}

Ming-Tsang Wu, I-Fang Mao, Chi-Kung Ho, David Wypij, Pey-Ling Lu, Thomas J Smith, Mei-Lien Chen, David C Christiani

\begin{abstract}
Objectives-To investigate the relation of individual occupational exposure to total particulates benzene soluble fraction (BSF) of ambient air with urinary 1-hydroxypyrene (1-OHP) concentrations among coke oven workers in Taiwan.

Methods-80 coke oven workers and 50 referents were monitored individually for the BSF of breathing zone air over three consecutive days. Exposures were categorised as high, medium, or low among coke oven workers based on exposure situations. The high exposure group $(n=18)$ worked over the oven. The medium and low exposure groups $(n=41$ and $n=21)$ worked at the side of the oven for $>4$ hours and $<4$ hours a day, respectively. Urine was collected before the shift on the morning of day 1 and after the shift on the afternoon of day 3 to find the change of 1-OHP concentrations across the shift.
\end{abstract}

Results-The median (range) changes of urinary 1-OHP concentrations across the shift for various exposure situations $(\mu \mathrm{g} / \mathrm{g}$ creatinine) were as follows: high 182 (7 to 3168); medium 9 (-8 to 511); low 7 (-6 to $28)$; and referents $0.2(-2$ to 72$)$. This change of urinary 1-OHP was highly associated with individual occupational exposure to the BSF in air $(r=0.74$ and $0.64, p$ $<0.001)$. The regression model showed significant effects of individual exposures to the BSF and alcohol consumption on urinary postshift 1-OHP after adjusting for preshift 1-OHP in the total population $(n=130)$. More exposure to the BSF led to higher postshift 1-OHP ( $p<0.001$ ); current drinkers of $>120 \mathrm{~g} /$ week had lower urinary postshift 1-OHP than never and former drinkers $(p=0.01)$. A 10-fold increase in the average $\mathrm{BSF}$ in air resulted in about a 2.5-fold increase in postshift 1-OHP among the 80 coke oven workers. Conclusion-Urinary 1-OHP concentrations can be used as a good biomarker to assess individual exposure to the BSF in air. Alcohol drinking may modify the toxicokinetic pathway of the BSF; the effects of alcohol should be investigated further in occupational studies.

(Occup Environ Med 1998;55:461-467)

Keywords: benzene; soluble fraction; total particulates; urinary 1-hydroxypyrene; coke oven workers

Coke oven emissions containing polycyclic aromatic compounds (PAHs), are formed and released into the environment when coal is pyrolysed into coke. ${ }^{12}$ Thus coke oven workers, especially those working on the top of the battery, are at high risk of exposure to PAHs in the coke process. Some PAHs with four or more benzene rings are considered to be human carcinogens. ${ }^{3}$ Epidemiological studies have presented strong evidence that workers with long term exposures to coke oven emissions have a high incidence of cancer, especially lung and colon cancers. ${ }^{45}$

The US Occupational Safety and Health Administration (OSHA) has set a threshold limit value of $150 \mu \mathrm{g} / \mathrm{m}^{3}$ for the benzene soluble fraction (BSF) of total particulates for coke oven emissions. ${ }^{6}$ Ambient BSF is commonly used to evaluate adverse health effects caused by exposure to PAHs. ${ }^{2}$ Our previous study has shown that coke oven workers on the top of the battery were exposed to higher ambient BSF than other workers. ${ }^{7}$ Although the composition of PAHs varies by industry, the distribution of air PAHs is relatively stable in an individual workplace. ${ }^{89} \mathrm{Ny}$ et al found correlations of $0.84,0.81$, and 0.80 between air BSF and air total PAHs, pyrene, and benzo(a)pyrene, respectively, among 38 workers in a Soderberg Netherlands potroom. ${ }^{2}$ These high correlations suggest that air sampling of BSF can be representative for individual and total $\mathrm{PAH}$ profiles.

Polycyclic aromatic hydrocarbons are present in complex mixtures of more than 100 different compounds in the vicinity of coke ovens. ${ }^{10}$ It is not feasible to evaluate each constituent hazard independently in the atmosphere or with biological monitoring. Therefore, a suitable marker representative for the complete set of PAHs and a good indicator for mutagenic activity should be chosen. ${ }^{311}$ Benzo(a)pyrene has been shown to be a more potent carcinogen than pyrene, but it is transformed in the body to more than 20 metabolites. ${ }^{12}$ The four ring pyrene occurs in relatively high concentrations in PAH mixtures and is almost exclusively metabolised to 1-hydroxypyrene (1-OHP), which accounts for about $90 \%$ of the total urinary excretion of pyrene in all species studied so far, including humans. ${ }^{3}$ Additionally, Jongeneelen et al reported a high correlation between the urinary excretion of mutagens and the urinary 1-OHP (Spearman correlation coefficient $r=0.93$, $\mathrm{n}=12) .{ }^{13}$ The half life of $1-\mathrm{OHP}$ in urinary excretion of workers ranges from 6 to 35 hours; Jongeneelen et al suggested that the end of the workshift can give a reliable indication of the dose for the week. ${ }^{14}{ }^{15}$ Thus urinary 1-OHP has 
been used as a reliable biomarker of exposure to PAHs. ${ }^{2}$

Jongeneelen et al collected air and urine samples over three consecutive days for coke oven workers for the analysis of 1-OHP. ${ }^{14}$ They found a good relation between mean ambient pyrene concentration and total PAH concentration among the 47 coking workers (Pearson correlation coefficient $r=0.88$ ). However, the relation between air pyrene and end of shift urinary 1-OHP concentrations was not strong $(\mathrm{p}=0.21)$ among 42 coke oven workers after adjusting for preshift 1-OHP. They also found that intraindividual variability of the exposure was large: the average coefficient of variation of the pyrene concentration between three shifts of 47 workers was $68 \%$. However, Kang et al found a high association between urinary 1-OHP and air exposure categorised by job titles among 84 steel plant workers in Korea. ${ }^{16}$ In their study, the exposure was estimated by job category, so concurrent personal air sampling during collection of urine specimens was not available.

In our previous preliminary study, 13 subjects including 11 coke oven workers and two referents from an administrative area were monitored individually for breathing zone air $\mathrm{BSF}$ over three consecutive days and daily spot urine samples before and after the shift were also collected. We found that after adjusting for daily preshift 1-OHP concentrations, daily postshift 1-OHP concentrations were positively associated with daily air BSF among the 11 coke oven workers. ${ }^{17}$ Also, the change in urinary 1-OHP across the shift-defined as postshift 1-OHP on the third day minus preshift 1-OHP on the first day-was highly associated with individual mean occupational exposure to air BSF. Because there were few study subjects, the effect of other covariates such as smoking and alcohol consumption on the metabolism of 1-OHP was not comprehensively elucidated. Therefore, in this study, we further examine the relation between individual urinary postshift 1-OHP concentrations and individual average exposure of BSF in air for three consecutive days after the adjustment of urinary preshift 1-OHP among coke oven workers in a large steel company in Taiwan. We also evaluated other potential confounders including age, Quetelet's index, alcohol consumption, smoking, consumption of roasted meat, dermal exposure, use of respiratory protective devices, and the presence of liver diseases.

\section{Materials and methods}

STUDY SUBJECTS

Study participants were employed in a large steel company in southern Taiwan. The detailed study design has been described elsewhere. ${ }^{7}$ The exposed group comprised 88 coke oven workers who were currently working and had been employed for at least 3 months in the older of two coke oven plants. An external comparison group (referents) of 59 men, who had not visited either coke operation area in the past 3 months, participated voluntarily in the study from a large administrative area in the same company. The referents were employed about $2 \mathrm{~km}$ away from the coke operation areas. Seventeen study subjects (eight coke oven workers and nine referents) did not provide complete urine samples either before or after the shift and were excluded from the analyses. No significant differences in the demographic characteristics, including age, Quetelet's index, education level, smoking status, and alcohol consumption, of subjects with and without complete urine specimens were found. Therefore, the final study population consisted of 80 coke oven workers and 50 referents.

EXPOSURE ASSESSMENT

Personal breathing zone air samples were collected from study subjects by battery operated personal air sampling pumps. Air samples were taken in the day crews after 1.5 days off and in the rotation crews after 2 days off. Each shift consisted of 8 hours; the task was relatively constant during the shift. Most subjects were sampled for at least 6 hours during the complete working day and for 3 consecutive days between August 1995 and February 1996.

The sampling filters were stored at $4^{\circ} \mathrm{C}$ and transported and analysed at the Institute of Occupational and Safety Health of Taiwan in Taipei. The samples were analysed with OSHA analytical methods and are presented elsewhere. ${ }^{17}$

1-OHP IN URINE

Spot urine samples were collected just before the shift in the morning of the first day and after the shift in the afternoon of the third day during the air sampling. Urine samples were stored at $-68^{\circ} \mathrm{C}$ for the analysis of 1-OHP by high performance liquid chromatography equipped with a fluorescence detector (Hitachi F-1080, Japan). The detailed analytical method has been presented elsewhere. ${ }^{17}$ The limit of detection of urinary $1-\mathrm{OHP}$ was $0.42 \mathrm{ng} / \mathrm{ml}$ determined as the mean +3 SDs of 10 urine samples from unexposed urban residents. The measurements below a concentration of $0.42 \mathrm{ng} / \mathrm{ml}$ $(0.6 \%$ of coke oven workers and $19.8 \%$ of referents) were set at $0.21 \mathrm{ng} / \mathrm{ml}$, half of the detection limit. The recovery of the analyte was determined in spiked urine samples at three concentrations $(3.50,10.67,96.67 \mathrm{ng} / \mathrm{ml})$. The recovery (mean (SD) (coefficient of variation) (\%)) from three determinations was 110 (7) (6), 94 (4) (4), 84 (6) (7). Reproducibility of the analysis of 1-OHP in urine was established by a repeated analysis of three samples (coefficient of variation $=9 \%$ ).

The urinary creatinine was reacted with alkaline picrate and the creatinine-picrate complex was measured by spectrophotometry (Hitachi U-2000, Japan) at a wavelength of 520 $\mathrm{nm}$. The concentration of urinary 1-OHP was presented as $\mu \mathrm{g} / \mathrm{g}$ creatinine.

QUESTIONNAIRE INFORMATION

A self administered questionnaire was given during the second or third day of the personal air sampling. The completed questionnaire was 
checked immediately by researchers. If any item was left in the questionnaire, the subject was asked again. Subjects reported age, height, weight, distance of residence from the company, alcohol consumption, smoking habit, consumption of roasted meat, dermal exposure to coal tar, and regular use of respirators.

Subjects were asked about their average weekly alcohol consumption of spirits, wine, and beer over the past 6 months. Their weekly consumption of the different beverages was totalled as $\mathrm{g} 100 \%$ alcohol. Given that the half life of urine excretion of 1-OHP in workers ranged from 6 to 35 hours, ${ }^{14}{ }^{15}$ information on smoking habit, consumption of roasted meat, and dermal exposure to coal tar were reported in the week before the collection of urine specimens. The company provided single cartridge half masked respirators (3M company, St Paul, MN) for employees who worked in the coke operation areas, but there was no formal training and test fitting of the respirator. ${ }^{17}$ Although some workers claimed that they wore respirators most of the time during work, we found that the respirators were sometimes hung around their necks. ${ }^{17}$

The job classifications among coke oven workers included supervisor, wharfman, lidman, door repairman, body repairman, tar chaser, benchman, coke side machine operator, larry car operator, heater, temperature controller, quencher, and pusher. ${ }^{18}{ }^{19}$ Workers were

Table 1 Demographic data ( $(\%))$ by exposure situations among coke oven workers and referents

\begin{tabular}{|c|c|c|c|c|}
\hline & \multicolumn{4}{|c|}{ Exposure group } \\
\hline & $\begin{array}{l}\text { High } \\
(n=18)\end{array}$ & $\begin{array}{l}\text { Medium } \\
(n=41)\end{array}$ & $\begin{array}{l}\text { Low } \\
(n=21)\end{array}$ & $\begin{array}{l}\text { Referents } \\
(n=50)\end{array}$ \\
\hline \multicolumn{5}{|l|}{ Age (y): } \\
\hline$<38$ & $9(50)$ & $10(24)$ & $9(43)$ & $17(34)$ \\
\hline $38-43$ & $5(28)$ & $12(29)$ & $9(43)$ & 19 (38) \\
\hline$>43$ & $4(22)$ & $19(46)$ & $3(14)$ & $14(28)$ \\
\hline \multicolumn{5}{|c|}{ Quetelet's index $\left(\mathrm{kg} / \mathrm{m}^{2}\right)$ : } \\
\hline$<22$ & $5(28)$ & $8(19)$ & $8(38)$ & $9(18)$ \\
\hline $22-25$ & $10(56)$ & $15(37)$ & $7(33)$ & $27(54)$ \\
\hline$>25$ & $3(17)$ & $18(44)$ & $6(29)$ & $14(28)$ \\
\hline \multicolumn{5}{|c|}{ Residence distance from the company $(\mathrm{km})$ : } \\
\hline$\leqslant 5$ & $6(33)$ & $17(42)$ & $3(14)$ & $11(22)$ \\
\hline$>5$ & $12(67)$ & $24(58)$ & $18(86)$ & $39(78)$ \\
\hline \multicolumn{5}{|c|}{ Alcohol consumption (g/wk): } \\
\hline Never and former & $10(56)$ & $27(66)$ & $15(71)$ & $38(76)$ \\
\hline \multicolumn{5}{|l|}{ Current } \\
\hline$\leqslant 120$ & $4(22)$ & $7(17)$ & $4(19)$ & $5(10)$ \\
\hline$>120$ & $4(22)$ & $7(17)$ & $2(10)$ & $7(14)$ \\
\hline \multicolumn{5}{|l|}{ Viral infection: ${ }^{\star}$} \\
\hline No & $17(94)$ & $31(76)$ & $17(81)$ & $44(88)$ \\
\hline Yes & $1(6)$ & $10(24)$ & $4(19)$ & $6(12)$ \\
\hline \multicolumn{5}{|l|}{ Serum ALT (IU/1):† } \\
\hline$\leqslant 39$ & $11(61)$ & $31(76)$ & $18(86)$ & $38(76)$ \\
\hline$>39$ & $7(39)$ & $10(24)$ & $3(14)$ & $12(24)$ \\
\hline \multicolumn{5}{|c|}{ Smoking habit (cigarettes): $\ddagger$} \\
\hline No & $6(33)$ & $20(49)$ & $10(48)$ & $34(68)$ \\
\hline $1-60$ & $2(11)$ & $7(17)$ & $4(19)$ & $6(12)$ \\
\hline $61-120$ & $1(6)$ & $7(17)$ & $4(19)$ & $4(8)$ \\
\hline$>120$ & $9(50)$ & $7(17)$ & $3(14)$ & $6(12)$ \\
\hline \multicolumn{5}{|c|}{ Consumption of roasted meat: $\ddagger$} \\
\hline No & $16(89)$ & $39(95)$ & $20(95)$ & $49(98)$ \\
\hline Yes & $2(11)$ & $2(5)$ & $1(5)$ & $1(2)$ \\
\hline \multicolumn{5}{|c|}{ Dermal exposure to coal tar (days): $\ddagger$} \\
\hline No & 0 & $8(20)$ & $1(5)$ & - \\
\hline $1-3$ & $1(6)$ & $9(22)$ & $2(9)$ & - \\
\hline$>3$ & $17(94)$ & $24(59)$ & $18(86)$ & - \\
\hline \multicolumn{5}{|c|}{ Regular use of respirators: } \\
\hline No & $6(33)$ & $20(49)$ & $2(10)$ & - \\
\hline Yes & $12(67)$ & $21(51)$ & $19(90)$ & - \\
\hline
\end{tabular}

*No viral infection=both hepatitis B antigens (-) and anti-hepatitis C antibodies (-). †Serum ALT $=$ alanine aminotransferase; reference from the clinic of the company. $\ddagger$ Information was reported in the week before urine specimen collection. classified into four exposure categories on the basis of their exposure situations as follows:

High exposure group: worked topside of the oven (lidman, tar chaser, larry car operator).

Medium exposure group: worked at the side of the oven $>4$ hours a day (wharfman, door repairman, benchman, coke side machine operator, quencher, and pusher).

Low exposure group: worked at the side of the oven $<4$ hours a day and mostly remained in the control rooms (supervisor, body repairman, heater, temperature controller).

Referents: had not visited coke operation areas for at least 3 months.

LABORATORY TESTS

Blood samples from both coke oven workers and referents were obtained for liver function profiles, hepatitis B surface antigens (HBsAg), and anti-hepatitis C antibodies (anti-HCV). These were taken from the cubital vein in the morning after three consecutive days of exposure measurements. Subjects were instructed not to eat for at least 6 hours before blood sampling.

Liver function profiles including aspartate aminotransferase, alanine aminotransferase, r-glutamyl transpeptidase, alkaline phosphatase, and total bilirubin were determined by a Hitachi Autoanalyzer 7050 (Japan) on the same day. The HBsAg and anti-HCV were evaluated by commercial enzyme linked immunoassays from Behringwerke AG (Marburg, Germany) and General Biologicals (Taiwan), respectively, within 2 weeks of blood sampling. ${ }^{7}$

\section{STATISTICAL METHODS}

Geometric mean (GM) or median, geometric standard deviation (GSD), and range were used to describe the distribution of BSF and urinary 1-OHP concentrations based on the exposure situations as GM was more representative of the skewed distribution of data than was the arithmetic mean. Age (tertiles), Quetelet's index (tertiles), residence distance from the company, alcohol consumption, viral infection, serum alanine aminotransferase, smoking habit, consumption of roasted meat, dermal exposure, and regular use of respirators were examined.

Trend tests were used to compare BSF exposures before and after the shift, and changes across the shift of urinary 1-OHP concentrations (postshift on the afternoon of the third day minus preshift on the morning of the first day) after $\log _{10}$ transformation. Spearman correlation coefficients were used to study the relation of urinary 1-OHP concentrations before and after the shift, and changes across the shift with average BSF in air.

Concentrations of urinary preshift 1-OHP were $\log _{10}$ transformed to normalise their distributions before regression analysis. The relation of concentrations of urinary postshift $1-\mathrm{OHP}$ with average BSF in air and other variables in the total population $(\mathrm{n}=130)$ and among coke oven workers $(n=80)$, respectively, was investigated in multiple linear regression models after adjusting for concentrations of urinary preshift 1-OHP. We did not 
Table 2 Ambient geometric mean (GSD) (range) benzene soluble fraction (BSF) of total particulates, before and after the shift, and change across the shift of 1-hydroxypyrene $(1-O H P)$ by exposure situations among coke oven workers and referents

\begin{tabular}{|c|c|c|c|c|}
\hline & \multicolumn{3}{|c|}{ Exposure groups } & \multirow{2}{*}{$\begin{array}{l}\text { Referents } \\
(n=50)\end{array}$} \\
\hline & High $(n=18)$ & Medium $(n=41)$ & $\operatorname{Low}(n=21)$ & \\
\hline $\operatorname{BSF}\left(\mu \mathrm{g} / \mathrm{m}^{3}\right)^{\star \star \star}$ & $\begin{array}{l}528(2.7) \\
(144-6309)\end{array}$ & $\begin{array}{l}74(2.5) \\
(11-1330)\end{array}$ & $\begin{array}{l}49(1.6) \\
(16-111)\end{array}$ & $\begin{array}{l}10(2.2) \\
(1-37)\end{array}$ \\
\hline $\begin{array}{l}\text { Preshift 1-OHP }(\mu \mathrm{g} / \mathrm{g} \\
\mathrm{cr})^{\star \star \star}\end{array}$ & $\begin{array}{l}29(3.2) \\
(1-101)\end{array}$ & $\begin{array}{l}5(2.1) \\
(0.7-23)\end{array}$ & $\begin{array}{l}3(2.4) \\
(0.3-24)\end{array}$ & $\begin{array}{l}0.7(2.5) \\
(0.1-4)\end{array}$ \\
\hline $\begin{array}{l}\text { Postshift 1-OHP }(\mu \mathrm{g} / \mathrm{g} \\
\mathrm{cr})^{\star \star \star}\end{array}$ & $\begin{array}{l}199(3.8) \\
(8-3261)\end{array}$ & $\begin{array}{l}13(3.8) \\
(0.2-520)\end{array}$ & $\begin{array}{l}11(2.0) \\
(3-31)\end{array}$ & $\begin{array}{l}1(3.3) \\
(0.1-72)\end{array}$ \\
\hline $\begin{array}{l}\text { Across shift change of } \\
1-\mathrm{OHP}(\mu \mathrm{g} / \mathrm{g} \mathrm{cr})^{\star \star \star}\end{array}$ & $\begin{array}{l}182 \dagger \\
(7 \text { to } 3168)\end{array}$ & $\begin{array}{l}9 \dagger \\
(-8 \text { to } 511)\end{array}$ & $\begin{array}{l}7 \dagger \\
(-6 \text { to } 28)\end{array}$ & $\begin{array}{l}0.2 \dagger \\
(-2 \text { to } 72)\end{array}$ \\
\hline
\end{tabular}

$\star \star \star \mathrm{p}<0.001$ for trend test on $\log$ transformed variables from the referents to the high exposure group (negative values excluded for across shift change of 1-OHP).

†Medians are presented instead of GM due to 4,2 , and 17 negative values in medium and low exposure groups and referents, respectively.

GSD is a multiplicative factor for the GM, not an additive factor such as SD.

find a significant correlation between average $\mathrm{BSF}$ in air and dermal exposure to coal tar, so the dermal exposure was still evaluated in the model among the 80 coke oven workers. Smoking habit was highly associated with average BSF in air in the total population and among coke oven workers, and was associated with exposure situations and preshift 1-OHP concentrations in the total population. To avoid the introduction of collinearity, we did not include this variable in the regression models.

The Wilcoxon rank sum test was used to examine differences in urinary 1-OHP before and after the shift between current smokers and never and former smokers in the nondrinking referents. The data were analysed with the SAS statistical package. ${ }^{20}$ All $\mathrm{p}$ values are two sided.

\section{Results}

Table 1 shows the demographic data categorised by exposure situations. Referents had a lower prevalence of current smoking and consumption of roasted meat than the three exposure groups. The mean BSF concentrations by exposure situations were: high exposure group $528 \mu \mathrm{g} / \mathrm{m}^{3}$; medium exposure group $74 \mu \mathrm{g} / \mathrm{m}^{3}$; low exposure group $49 \mu \mathrm{g} / \mathrm{m}^{3}$; and referents $10 \mu \mathrm{g} / \mathrm{m}^{3}$ (table 2). The median change of concentrations of urinary 1-OHP across the shift $(\mu \mathrm{g} / \mathrm{g}$ creatinine) for the four groups were $182,9,7$, and 0.2 , respectively. The topside oven workers had the highest mean urinary 1-OHP values before and after the shift, and median changes across the shift, and there was a positive trend from the referents to the high exposure group for each of these outcomes (trend test, $\mathrm{p}<0.001$ ). Twenty three negative values in change of concentrations of urinary 1-OHP across the shift were excluded in this analysis (six coke oven workers (range: -1.3 to $-8(\mu \mathrm{g} / \mathrm{g}$ creatinine) and $17 \mathrm{ref}-$ erents (range: -0.04 to $-1.6(\mu \mathrm{g} / \mathrm{g}$ creatinine)). Figure 1 shows that $10 \%$ and $34 \%$ of concentrations of urinary postshift 1-OHP were lower than preshift values in medium and low exposure groups and referents, respectively.

Individual average BSF was highly correlated with preshift, postshift, and across shift urinary 1-OHP concentrations. The more the ambient BSF exposure, the higher

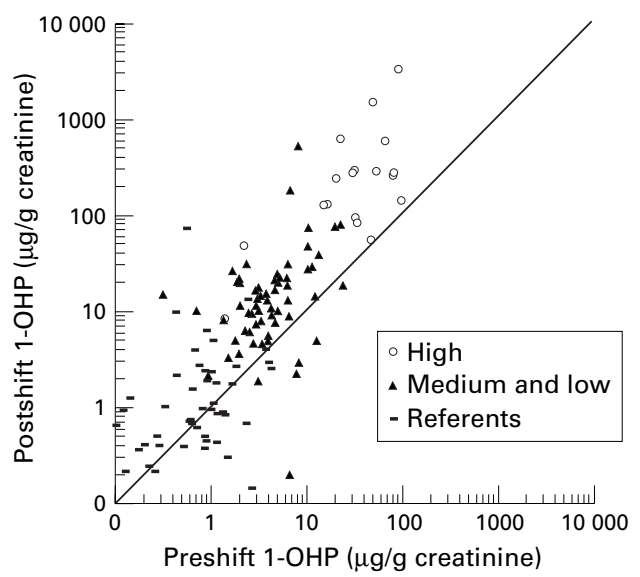

Figure 1 Relations between concentrations of urinary 1-hydroxypyrene before and after the shift by exposures.

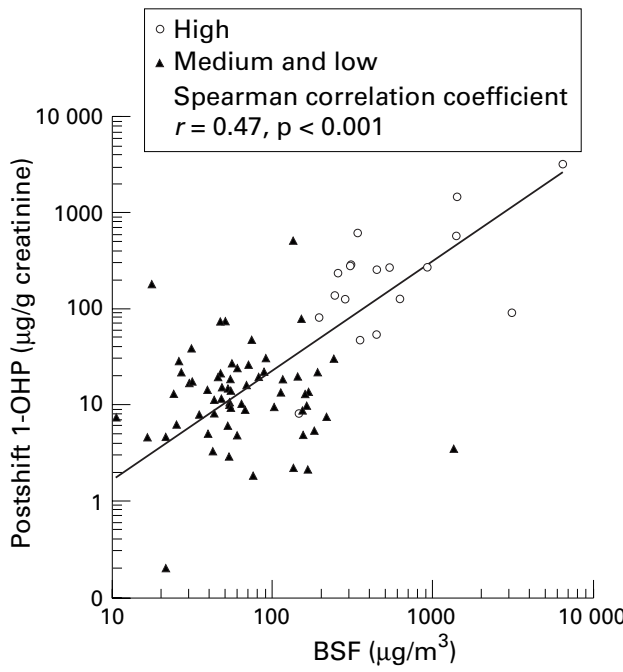

Figure 2 Relations between concentrations of urinary 1-hydroxypyrene after the shift and ambient average benzene soluble fraction (BSF) of total particulates by exposures among the 80 coke oven workers. Regression line shown.

were the concentrations of urinary 1-OHP before, after, and across the shift (Spearman correlation coefficients $r=0.74,0.74,064$, respectively, in the total population $(n=130)$; and $r=0.47,0.47,0.42$, respectively, in the coke oven workers $(n=80), p<0.001$ for each, fig 2).

Given that the half life of urinary 1-OHP excretion in workers ranged from 6-35 hours, ${ }^{14}{ }^{15}$ we attempted to weight BSF in air differently over the 3 days, based on the 12 and 24 hour half life, and examined the different contributions of urinary 1-OHP after and across the shift. The formulas were: $0.0625 \times 1 \mathrm{st}$ day $\mathrm{BSF}+0.25 \times 2$ nd day $\mathrm{BSF}+1 \times 3$ rd day $\mathrm{BSF}$ and $0.25 \times 1$ st day $\mathrm{BSF}+0.5 \times 2$ nd day $\mathrm{BSF}+1 \times 3 \mathrm{rd}$ day BSF. This led to a slight reduction of rank correlation coefficients between urinary 1-OHP after and across the shift in the total population and among coke oven workers, compared with the average BSF (data not shown).

Multiple regression analysis indicated that occupational exposure to ambient BSF and alcohol consumption were significant predictors of concentrations of urinary postshift 
Table 3 Predictors of $\log _{10}$ transformed postshift urinary 1-hydroxypyrene (1-OHP) concentrations by multiple linear regressions in the total population and among coke oven workers

\begin{tabular}{|c|c|c|c|c|c|c|}
\hline & \multicolumn{3}{|l|}{ Total $(n=130)$} & \multicolumn{3}{|c|}{ Coke oven workers $(n=80)$} \\
\hline & $\beta(S E \beta)^{\star}$ & p Value & $r^{2}$ & $\overline{\beta(S E \beta)^{\star}}$ & p Value & $r^{2}$ \\
\hline Model A: & & & 0.56 & & & 0.36 \\
\hline Intercept & -0.77 & & & -0.26 & & \\
\hline Average BSF† & $1.00(0.08)$ & $<0.001$ & & $0.81(0.12)$ & $<0.001$ & \\
\hline Model B: & & & 0.69 & & & 0.56 \\
\hline Intercept & -0.21 & & & -0.02 & & \\
\hline Average BSF & $0.46(0.10)$ & $<0.001$ & & $0.39(0.13)$ & 0.002 & \\
\hline Preshift & $0.75(0.10)$ & $<0.001$ & & $0.74(0.13)$ & $<0.001$ & \\
\hline Model C: & & & 0.71 & & & 0.57 \\
\hline Intercept & -0.10 & & & 0.01 & & \\
\hline Average BSF & $0.40(0.10)$ & $<0.001$ & & $0.37(0.13)$ & 0.004 & \\
\hline Preshift & $0.84(0.10)$ & $<0.001$ & & $0.79(0.13)$ & $<0.001$ & \\
\hline Alcohol-1s & $-0.03(0.12)$ & 0.79 & & $0.06(0.14)$ & 0.67 & \\
\hline Alcohol-2S & $-0.36(0.13)$ & 0.01 & & $-0.21(0.16)$ & 0.18 & \\
\hline
\end{tabular}

$\star \mathrm{SE} \beta=$ standard error of $\beta$ coefficient.

†Average $\mathrm{BSF}=\log _{10}$ transformed ambient average benzene soluble fraction of total particulates. $\ddagger$ Preshift $=\log _{10}$ transformed preshift 1-OHP.

\Alcohol-1 = current drinkers reporting $\leqslant 120 \mathrm{~g} /$ week $v$ never and former drinkers; Alcohol-2 = current drinkers reporting $>120 \mathrm{~g} /$ week $v$ never and former drinkers.

Table 4 Predictors of $\log _{10}$ transformed 1-hydroxypyrene (1-OHP) concentrations after the shift by multiple linear regressions in the referents $(n=50)$

\begin{tabular}{llll}
\hline Determinants & $\beta(S E \beta)^{\star}$ & $p$ Value & $\begin{array}{l}\text { Overall } \\
\text { model }\left(r^{2}\right)\end{array}$ \\
\hline Intercept & 0.48 & - & 0.26 \\
Preshift $\dagger$ & $0.54(0.19)$ & 0.007 & - \\
Residence distance from the company $\neq$ & $-0.34(0.16)$ & 0.04 & - \\
Alcohol-1§ & $-0.24(0.23)$ & 0.29 & - \\
Alcohol-2\} $&{-0.34(0.22)} &{0.13} &{-} \\
{\hline}$
\end{tabular}

$\star$ SE $\beta=$ standard error of $\beta$ coefficient.

†Preshift $=\log _{10}$ transformed preshift 1-OHP.

$\ddagger$ Residence distance from the company $\geqslant 5 \mathrm{~km} v \leqslant 5 \mathrm{~km}$.

AAlcohol-1 and Alcohol-2 as described in table 3.

1-OHP after adjusting for preshift concentrations in the total population $(n=130$, table 3$)$. More BSF exposure led to higher postshift $1-\mathrm{OHP}$ concentrations ( $\mathrm{p}<0.001)$; current drinkers with $>120 \mathrm{~g} /$ week had lower concentrations than never and former drinkers $(p=0.01)$. However, consumption of roasted meat and dermal exposure to coal tar in the week before collection of urine specimens were not significantly associated with concentrations of urinary postshift 1-OHP. Other variables including age, Quetelet's index, hepatic viral infection, abnormal serum alanine aminotransferase, and regular use of respirators were also not independent predictors of concentrations of urinary postshift 1-OHP.

Among the 80 coke oven workers, occupational exposure to ambient BSF was a significant predictor of urinary postshift 1-OHP. A 10 -fold increase in average BSF in air resulted in about a 2.5 -fold increase in concentrations $\left(\exp \left((0.393) \cdot\left(\log _{10}(10)\right)=2.5\right.\right.$ in model $\mathrm{B}$ of table 3). However, alcohol consumption was not a significant predictor of urinary postshift 1-OHP among coking workers.

In multiple linear regression with $\log _{10}$ transformed postshift 1-OHP concentrations in the referents $(n=50)$, only preshift 1-OHP concentrations and residence distance from the company significantly predicted postshift 1-OHP concentrations (table 4). Residence farther away from the company was associated with lower 1-OHP concentrations ( $p=0.04)$. Alcohol consumption marginally predicted postshift 1-OHP concentrations. Neither the concentrations in ambient air BSF nor smok- ing in the week before collection of urine specimens significantly contributed to the postshift $1-\mathrm{OHP}$ concentrations in referents. Among the non-drinking referents $(\mathrm{n}=38)$, the mean (range, $\mu \mathrm{g} / \mathrm{g}$ creatinine) postshift $1-\mathrm{OHP}$ concentration in non-smokers $(\mathrm{n}=33)$ was 1.4 (0.2 to 72.4 ), which was slightly, but not significantly, higher than 0.7 (0.4 to 1.8$)$ in smokers $(n=5)$ (Wilcoxon rank sum test; $\mathrm{p}=$ $0.20)$.

\section{Discussion}

We found that the more the ambient BSF exposure, the higher were the concentrations of urinary 1-OHP preshift, postshift, and changes across the shift. In particular, the topside oven workers, exposed to the highest ambient BSF, also had the highest concentrations of urinary 1-OHP preshift, postshift, and the highest change across the shift. Also, individual current BSF exposures are highly associated with postshift urinary 1-OHP after adjusting for preshift 1-OHP. More BSF exposure led to higher postshift 1-OHP. Therefore, individual biological monitorings and exposure situations can both be used, with different levels of precision, as tools for exposure assessment to link with health consequences in epidemiological studies of coke oven and steel plant workers.

Mean concentration of BSF $\left(\mu \mathrm{g} / \mathrm{m}^{3}\right)$ among topside oven workers was 528 (range: 144 to 6309) in the coke oven battery. These values are comparable with published mean values of $500 \mu \mathrm{g} / \mathrm{m}^{3}$ with a range of 100 to $5700 \mu \mathrm{g} / \mathrm{m}^{3}$ in topside workers at one coke oven, ${ }^{13}$ but are higher than those of more recently reported mean values of 240 to $430 \mu \mathrm{g} / \mathrm{m}^{3}$ for three high exposure job titles in a coke oven battery in Korea. $^{16}$

Although Jongeneelen et al found that alcohol consumption was not an indicator of the metabolism of pyrene, ${ }^{14}$ in our study we found that heavy drinkers $(\geqslant 120 \mathrm{~g} /$ week) had significantly lower postshift concentrations of urinary 1-OHP than never and former drinkers in the total population $(n=130)$. However, this association was not present in coke oven workers $(n=80)$. Research has shown that 1-OHP is a major metabolite of pyrene, ${ }^{3}$ but other metabolites including trans-4,5-dihydro-4,5dihydroxypyrene, 1,6- and 1,8-dihydroxypyrene, etc were also found in the urine and bile of both rats and rabbits treated with pyrene. $^{21} 22$ Therefore, alcohol might induce some hepatic microsomal enzymes that further metabolise 1-OHP to other metabolites or transfer to other pathways of metabolism. Direct competition of enzymes between pyrene and alcohol is unlikely, because it is prohibited for coke oven workers to drink during work. When ambient pyrene is above a certain level, the effect of heavy drinking on concentrations of postshift urinary 1-OHP is absent. Given the few heavy drinkers in our study, the role of alcohol in 1-OHP metabolism needs further investigation.

We found that much of the variability of postshift 1-OHP was determined by preshift 1-OHP (model C). This may be caused by a carryover effect of the exposure in the previous 
week. Jongeneelen et al studied an operator who worked in a wood preserving plant and collected his urine daily to measure 1-OHP concentrations in two different periods: before and after work for 1 week and during a 17 day period away from work. ${ }^{23}$ They suggested that the excretion of 1-OHP is biphasic: a fast excreting component with a half life of 1-2 days and a slow-excreting component with a half life of 16 days. In our study, the high initial 1-OHP concentrations of some workers were probably due to high exposure to coke oven emissions previously or due to large body burdens in long term storage that delayed excretion of previous exposure periods. ${ }^{2}$

Buchet et al found that excretion of 1-OHP doubled when exposure to pyrene in air increased 10-fold among 102 workers in a coke production and a graphite electrode manufacturing plant in Belgium. ${ }^{24}$ The data are similar to our findings that a 10 -fold increase in average BSF in air led to about a 2.5-fold increase in postshift 1-OHP among the 80 coke oven workers. Because the distribution of air PAHs are relatively stable in an individual workplace,${ }^{89}$ similar results are present in these two studies. However, the increase in postshift 1-OHP concentrations is not of the same magnitude as the increase in average BSF in air. Possible reasons are that $1-\mathrm{OHP}$ is eliminated through other routes such as the biliary tract, or pyrene is metabolised to other products besides 1-OHP in humans. ${ }^{11}$

A trace amount of 1-OHP was found in the urine of referents. Leading determinants of postshift 1-OHP were preshift 1-OHP and distance of residence from the company. The mean (range, $\mu \mathrm{g} / \mathrm{g}$ creatinine) of postshift 1-OHP concentrations in non-smoking referents $(n=33)$ was $1.4(0.2$ to 72.4$)$, higher than those reported in several other studies: 0.3 (0.02 to 1.8$)$ in 14 non-smoking steel rolling workers $^{14}$ and $0.5(0.04$ to 1.3$)$ in 52 non-smoking male referents. ${ }^{23}$ Southern Taiwan is a highly industrialised area. We suspected that high concentrations of postshift 1-OHP in non-smokers were due to environmental exposures to PAHs.

No effect of smoking was found on the 1-OHP concentrations in urine of workers in a Soderberg potroom, ${ }^{2}$ whereas a significantly higher concentration of urinary 1-OHP was found among workers who smoked at a steel plant. ${ }^{16}$ In the present study, smoking in the week before collection of urine specimens could not be well evaluated in the regression models as the subjects exposed to higher coke oven emissions also smoked more cigarettes. However, we found that smoking and current BSF in air did not have a significant effect on the postshift 1-OHP in the referents who did not drink $(\mathrm{n}=38)$. This result was unexpected, because one cigarette contains about $50-200$ ng pyrene. ${ }^{16}$ Given the few non-drinking referents, we need to further examine the effects of cigarette smoking on the formation of 1-OHP in the rest of the population.

The amount of roasted meat consumed by the study subjects was relatively small. Infrequent consumption of foods with a high $\mathrm{PAH}$ content, such as roasted meat, is characteristic of the Taiwan diet and similar to the Korean diet. ${ }^{16}$ VanRooij et al have estimated individual dermal and inhaled uptake of PAHs among 12 coke oven workers. ${ }^{25}$ Dermal exposure was measured with exposure pads at six skin sites: the jaw of neck, shoulder, upper arm, wrist, groin, and ankle. They found that a large proportion of PAHs was absorbed through the skin. However, in our study, skin contamination of PAHs was estimated by questionnaire. This method of estimation of exposure is imprecise and may result in a bias toward the null.

Serum alanine aminotransferase values and hepatic viral infection did not significantly predict 1-OHP concentrations in this study. Although an increase of the serum alanine aminotransferase is a consequence of increased hepatic membrane permeability as well as membrane leakage, ${ }^{26}$ perhaps it does not influence the amount and activity of microsomal enzymes that metabolise PAHs. ${ }^{21}$ Jongeneelen et al reported that workers wearing airstream helmets had lower postshift $1-\mathrm{OHP},{ }^{14}$ whereas $\mathrm{Ny}$ et al reported that the increase of urinary 1-OHP was greater in those who used facial respirators. ${ }^{2}$ Our report did not show that wearing respirators decreased the absorption of PAHs. One reason for this may be that a poor respirator fit due to high temperature and perspiration results in a large variability between people in the effects of using a respirator.

This study shows that BSF in air, as a surrogate of coke oven emissions, is highly correlated with concentrations of postshift urinary 1-OHP. A 10-fold increase in average BSF in air resulted in about a 2.5-fold increase in postshift 1-OHP among the 80 coke oven workers. We conclude that the measurement of postshift $1-\mathrm{OHP}$ in urine can be used as a surrogate for current occupational exposure to coke oven emissions after adjustment of preshift 1-OHP. Furthermore, alcohol consumption may influence the toxicokinetics of pyrene and should be examined in future studies. This study was supported by grants from the Department of
Health, Taiwan, Republic of China (DOH83-HP-116), the Health, Taiwan, Republic of China (DOH83-HP-116), the
National Science Council, Taipei (NSC 85-2621-B-010-001Z), a Chinese Steel Company Industrial Safety and Health Award, and grants ES00002 and 05947 from the NIH. We gratefully acknowledge Ms Yueh-Ching Chang of the Kaohsiung Medical College for assistance with collecting air samples and $\mathrm{Mr}$ Chyun-Hsien $\mathrm{Fu}, \mathrm{Mr}$ Fei-Jenn $\mathrm{Wu}$, and $\mathrm{Ms}$ Chyong-Sheue Yang for help with drawing blood and the analysis of liver function profiles, officials in the Department of Analytical Chemistry, National Institute of Occupational Safety and Health, Taiwan, for help with analysing BSF and Drs Richard R Monson and Yue-Liang Leon Guo for their thoughtful comments. We are also indebted to the workers of the iron and steel company who participated in this study.

1 US Department of Labor. Occupational Safety and Health Administration. OSHA analytical methods manual. Cincinatti: OSHA, 1990;3:58.

2 Ny ET, Heederik D, Kromhout H, et al. The relationship between polycyclic aromatic hydrocarbons in air and in urine of workers in a Soderberg potroom. Am Ind Hyg Assoc f 1993;54:277-84.

3 Boogaard PJ, Sittert NJ. Exposure to polycyclic aromatic hydrocarbons in petrochemical industries by measurement of urinary 1-hydroxypyrene. Occup Environ Med 1994;51: 250-8.

4 Chau N, Bertrand JP, Figueredo A, et al. Mortality in retired coke oven plant workers. Br F Ind Med 1993;50:127-35.

5 Berger J, Manz A. Cancer of the stomach and the Berger J, Manz A. Cancer of the stomach and the
colon-rectum among workers in a coke gas plant. Am $\mathcal{F}$ Ind Med 1992;22:825-34. 
6 US Department of Labor. Occupational Safety and Health Administration. Final occupational safety and health standard for exposure to coke oven emissions. Federal Reg-

7 ister $1976,41: 46742-93$.

7 Wu MT, Mao IF, Wypij D, et al. Serum liver function profiles in coking workers. $\mathrm{Am} \mathcal{F}$ Ind $\mathrm{Med}$ 1997;32:478-86

8 Lindstedt G, Sollenberg J. Polycyclic aromatic hydrocarbons in the occupational environment; with special reference to benzo(a)pyrene measurements in Swedish Industry. Scand $\mathcal{f}$ Work Environ Health 1982;8:119.

9 Broddin G, Van Vaeck L, Van Cauwenberghe K. On the size distribution of polycyclic aromatic hydrocarbon containing particulates from a coke oven emissions source. Atmos Environ 1977;11:1061-4.

10 World Health Organisation. IARC monographs on the evaluation of the carcinogenic risk of chemicals to humans: polynuclear aromatic compounds, part 3, Industrial exposures in aluminum production, coal gasification, coke production, and iron and steel production, coal gasification, coke production,

11 Buckley TJ, Lioy PJ. An examination of the time course from human dietary exposure to polycyclic aromatic hydrocarbons to urinary elimination of 1-hydroxypyrene. Br F Ind Med 1992;49:113-24.

12 Jongeneelen FJ, Anizon RBM, Leijdekkers CM, et al. 1-Hydroxypyrene in human urine after exposure to coal tar and a coal tar derived product. Int Arch Occup Environ Health 1985;57:47-55.

13 Jongeneelen FJ, Bos RP, Anizon RB, et al. Biological monitoring of polycyclic aromatic hydrocarbons-metabolites in urine. Scand $\mathcal{F}$ Work Environ Health 1986;12:137-43.

14 Jongeneelen FJ, van Leeuwen FE, Oosterink S, et al. Ambient and biological monitoring of cokeoven workers: determinants of the internal dose of polycyclic aromatic hydrocarbons. Br F Ind Med 1990;47:454-61.

15 Jongeneelen FJ. Biological exposure limit for occupational exposure to coal tar pitch volatiles at cokeovens. Int Arch exposure to coal tar pitch volatiles at
Occup Environ Health 1992;63:511-6.
16 Kang DH, Rothman N, Cho SH, et al. Association of exposure to polycyclic aromatic hydrocarbons (estimated from ob category) with concentration of 1-hydroxypyrene glucuronide in urine from workers at a steel plant. Occup

17 Wu MT, Wypij D, Ho CK, et al. Temporal changes in urinary 1-hydroxypyrene concentrations in coke-oven workers. Cancer Epidemiol Biomarkers Prev 1998;7:167-9.

18 Fannick N, Gonshor LT, Shockley Jr J. Exposure to coal tar pitch volatiles at coke ovens. Am Ind Hyg Assoc $\mathcal{F} 1972 ; 33$ : 461-8.

19 Keimig DG, Slymen DJ, White O. Occupational exposure to coke oven emissions from 1979-83. Arch Environ Health 1986;41:363-7.

20 SAS Institute. SAS Language guide for personal computers, release $6.03 \mathrm{ed}$. Cary, NC: SAS Institute, 1988.

21 Boyland E, Sims P. Metabolism of polycyclic compoundsthe metabolism of pyrene in rats and rabbits. Biochem $f$ 1964;90:391-8.

22 Harper KH. The metabolism of pyrene. $\mathrm{Br} f$ Cancer 1957;11:499-507.

23 Jongeneelen FJ, Anizon RBM, Scheepers FTJ, et al. 1-Hydroxypyrene in urine as a biological indicator of expoure to polycyclic aromatic hydrocarbons in several work environments. Ann Occup Hyg 1988;32:35-43.

24 Buchet JP, Gennart JP, Mercado-Calderon F, et al. Evaluation of exposure to polycyclic aromatic hydrocarbons in a coke production and a graphite electrode manufacturing plant: assessment of urinary excretion of 1-hydroxypyrene as a biological indicator of exposure. $\mathrm{Br} f$ Ind Med 1992;49:761-8.

25 VanRooij JG, Bodelier-Bade MM, Jongeneelen FJ. Estimation of individual dermal and respiratory uptake of polycyclic aromatic hydrocarbons in 12 coke oven workers. $B r f$ Ind Med 1993;50:623-32.

26 Price CP, Alberti KGMH. Biochemical assessment of liver function. In: Wright R, Millward-Sadler GH, Alberti KGMH, eds. Liver and biliary disease. Philadelphia; WB Saunders 1979;470-3. 